\title{
Interventions to Reduce Anxiety in Postpartum Mother
}

\section{Denis Mulanita Pratiwi' ${ }^{1}$, Sri Rejeki², Achmad Zulfa Juniarto ${ }^{1}$}

1 Program Magister Keperawatan, Fakultas Kedokteran, Universitas Diponegoro

2 Fakultas Ilmu Keperawatan dan Kesehatan, Universitas Muhammadiyah Semarang

\section{Article Info}

Article History:
Submitted: Nov $2^{\text {nd }}, 2020$
Accepted: Jan $1^{\text {st }}, 2021$
Published: Feb $13^{\text {th }}, 20$
Keywords:
Intervention; Anxiety;
Postpartum

Postpartum

\begin{abstract}
Postpartum stress mostly experienced by first-time mothers. This stressful condition indicates that some new mothers experience emotional changes, sometimes feeling happy and at times almost feeling sad for no reason. This study aims to understand a deeper understanding of interventions for postpartum anxiety. A literature review was conducted by looking for literature related to the theme taken. The articles obtained were 9 quantitative studies, 7 articles from Indonesia and 2 articles from other countries. Most interventions are massage therapy and various types of relaxation (aromatherapy, hypnotherapy, yoga) to reduce the level of anxiety of postpartum mothers. This review helps provide several interventions that can be carried out on postpartum mothers in a nonpharmacological, simple and effective interventions that can be carried out in postpartum mothers in reducing the level of anxiety of postpartum mothers, besides that it can improve sleep quality, reduce levels of depression, reduce stress, can increase breast milk production and increase comfort in postpartum mothers.
\end{abstract}

\section{PENDAHULUAN}

Dalam periode postpartum, 85\% ibu postpartum dapat mengalami gangguan psikologi. Ada yang menunjukkan gejala yang ringan dan tidak berlangsung lama, namun adapula sampai 10 hingga 15\% mengalami gejala yang lebih signifikan seperti depresi atau kecemasan. Angka kejadian kecemasan pada ibu postpartum secara global antara 10-15\% [1]. Beberapa negara di dunia membuat laporan hanya beberapa kejadian kecemasan postpartum tetapi ada juga beberapa negara yang membuat laporan insiden yang lebih banyak [2]. Menurut
WHO, ibu melahirkan yang mengalami kecemasan postpartum ringan diantara 10 per 1000 kelahiran yang hidup serta yang mengalami kecemasan postpartum sedang ataupun berat diantara 30 sampai 200 per 1000 kelahiran.

Angka kejadian kecemasan lebih sering muncul dibanding dengan depresi. Kecemasan postpartum serta depresi mempunyai efek pada seluruh perkembangan mental pada anak-anak yang dilahirkan. Kecemasan yang terjadi pada fase postpartum penyebabnya dikarenakan terdapatnya proses perubahan peran wanita dan pria dalam

Corresponding author:

Achmad Zulfa Juniarto

achmadzulfajuniarto@lecturer.undip.ac.id

Media Keperawatan Indonesia, Vol 4 No 1, February 2021

e-ISSN: 2615-1669

ISSN: 2722-2802

DOI: $\underline{10.26714 / \mathrm{mki} .4 .1 .2021 .62-71}$ 
proses menjadi orang tua, wanita dan pria mengalami penyesuaian diri yang sangat besar terhadap hubungan mereka dengan orang lain.

Kebanyakan ibu primipara cenderung mengalami stres postpartum. Kondisi stres ini menunjukkan bahwa sebagian ibu primipara menghadapi perubahan perasaan emosional seperti merasakan bahagia tetapi juga merasakan kesedihan yang tanpa sebab di waktu yang bersamaan. Perubahan perasaan emosional ini terlihat dengan terdapatnya rasa khawatir akan perubahan perhatian dari suaminya ataupun keluarga dekat yang teralihkan dikarenakan adanya kehadiran bayi, rasa takut tubuhnya menjadi tidak ideal, rasa khawatir tidak bisa memberi ASI untuk bayinya, rasa gelisah serta kehilangan minat untuk melakukan kegiatan seharihari, mempunyai rasa terabaikan oleh suaminya serta keluarga dekat, merasakan lelah serta kehilangan energi yang berkepanjangan, menurunnya konsentrasi serta kemampuan berpikir, merasakan bersalah serta tidak berguna, dan insomnia.

Fenomena yang terjadi menunjukkan kecemasan postpartum yang tidak sesegera mungkin diatasi dapat berlanjut menjadi depresi postpartum yang akan membahayakan ibu dan bayinya.

Tujuan literature review ini adalah untuk mendapatkan pemahaman yang lebih tentang intervensi non farmakalogis untuk mengatasi kecemasan ibu postpartum.

\section{METODE}

Metode pada penelitian ini adalah literature review. Dalam metode ini dilakukan dengan melakukan analisis tentang intervensi yang dipergunakan untuk menurunkan tingkat kecemasan pada ibu postpartum. Database yang digunakan dalam penyusunan literature review didapatkan dari database science direct, pubmed dan google scholar. Pencarian berfokus pada judul, kata kunci dan artikel yang sesuai pada jurnal yang telah ditentukan dari tahun 20162020.

Keyword yang digunakan dalam pencarian artikel yaitu intervensi, kecemasan dan postpartum. Hasil penelusuran pada science direct 1 artikel, pubmed 1 artikel dan google scholar 7 artikel. 


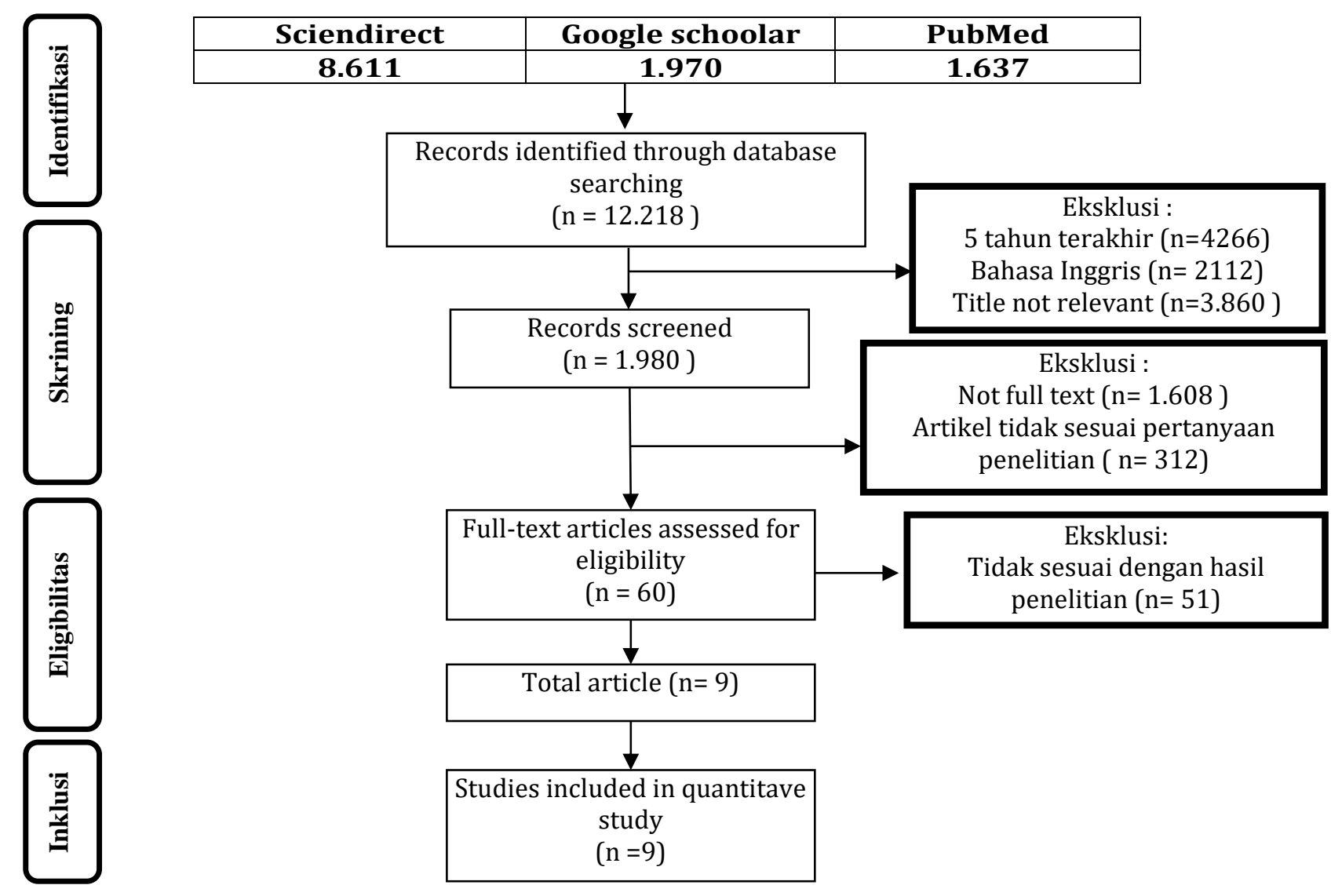

Gambar 1

Algoritma Pencarian Artikel

\section{HASIL}

Penelitian Chandra Sulistyorini (2020) menunjukkan bahwa ibu postpartum yang mengalami kecemasan dalam melakukan perawatan bayi diberikan kombinasi terapi totok wajah dengan aromaterapi lavender yang dilakukan satu kali dengan durasi 1520 menit memperlihatkan adanya perbedaan yang bermakna rata-rata skor kecemasan pada ibu postpartum sebelum serta sesudah dilakukan kombinasi terapi totok wajah dengan aromaterapi lavender [3].

Ridha Ariani (2018) menyatakan ibu postpartum yang tidak melakukan yoga selama kehamilan, memiliki kecemasan lebih tinggi dibandingkan dengan yang melakukakan yoga selama kehamilan yang menunjukkan bahwa terdapat perbedaan kecemasan [4].

Penelitian Lutfiana Puspita Sari (2019) menunjukkan bahwa ibu nifas yang diberikan hipnosis serta rileksasi dengan cara diberikan sugesti dan melakukan visualisasi serta harapan yang diinginkannya sehingga tingkat kecemasan serta stres yang dialaminya akan berkurang. Hal itu disebabkan oleh hormon kortisol yang mempunyai pengaruh terhadap stres dihambat dalam upaya produksinya dikarenakan adanya aktivasi syaraf para simpatis sehingga memproduksi hormon oksitosin serta endorpin. Ibu menjadi lebih tenang, nyaman, serta bahagia. Rileksasi pada ibu menyusui yaitu rileksasi hypnobreastfeeding adalah teknik rileksasi yang langsung menuju alam bawah sadar. 
Saat mencapai keadaan rileks yang dalam serta stabil, ibu dapat diberikan sugesti baru secara otomatis yang dapat mempengaruhi kehidupannya serta tindakannya sehari-hari tanpa disadari sehingga muncul rasa percaya diri menjadi seorang ibu serta dapat menjaga dan merawat bayinya dengan baik dengan memperhatikan nutrisi yang dibutuhkan oleh bayi [5].

Tina Mawardika (2020) menyatakan pada saat exercise relaksasi otot progresif, fokus seseorang dipusatkan untuk dapat membedakan sesuatu yang dirasakan saat sekelompok otot dibuat lemas serta membandingkan dengan saat otot-otot dalam kondisi ditegangkan. Dengan mengetahui tempat serta merasakan otot yang tegang, maka seseorang bisa merasakan hilangnya ketegangan yang merupakan salah satu respon kecemasan yang dirasakan dengan lebih jelas, saat rasa cemas menurun, status kesehatan psikologis ibu pun meningkat sehingga berimbas pada meningkatnya status kesehatan anaknya. Berdasarkan hasil penelitian tersebut maka disarankan bagi ibu postpartum dapat memanfaatkan relaksasi otot progresif sebagai terapi komplementer menurunkan kecemasan pada ibu postpartum [6].

Pada penelitian Sri Rahayu (2018) menyebutkan bahwa pemberian pemijatan endorphin membantu ibu menjadi lebih segar, rileks, serta nyaman pada fase postpartum. Hal ini disebabkan oleh pemberian pemijatan dapat menstimulasi tubuh untuk mengeluarkan hormon endorphin sebagai analgetik alami. Endorphin juga membuat perasaan menjadi lebih nyaman serta lebih baik sehingga dapat menurunkan kecemasan yang dirasakan oleh ibu postpartum. Kecemasan ibu postpartum bisa mencegah produksi colostrum, bahkan dapat juga mempengaruhi pertumbuhan bayi. Dengan dilakukan pemijatan dapat menstimulasi tubuh agar melepaskan hormon endorphin untuk mendapatkan kenyamanan [7].

\section{Menurut Siti Novy Romlah (2019)} menyatakan bahwa kejadian breast engorgement dapat dicegah dengan melakukan pemijatan oketani. Produksi ASI yang lancar serta tingkat kecemasan sebelum serta sesudah diberikan pemijatan oketani mengalami perbedaan. Kadar okstosin yang meningkat serta produksi ASI yang lancar disebabkan karena adanya perasaan rileks serta kenyamanan yang didapatkan ibu setelah diberikan pemijatan oketani [8].

Sementara itu, menurut Maryam Kianpour (2019) perbedaan rata-rata pada skor stres, kecemasan, dan depresi pasca persalinan berbeda antara kelompok studi dan kontrol pada titik waktu 2 minggu, 1 bulan, dan 3 bulan setelah melahirkan. Sehingga ratarata skor stres dan depresi postpartum menurun melalui waktu pada wanita setelah melahirkan. Oleh karena itu, meskipun mereka biasanya menurun seiring waktu, penurunan ini lebih tinggi dengan aromaterapi lavender, yang mencegah atau mengurangi komplikasi akibat stres, kecemasan, dan depresi pascapartum [9].

Fereshteh Jahdi (2016) menyatakan bahwa penerapan slow stroke back massage sangat efektif untuk menurunkan kecemasan ibu postpartum pada hari pertama [10]. 
Tabel 1

Sintesis Grid

\begin{tabular}{|c|c|c|c|c|c|}
\hline No & Penulis & Judul & Tujuan & Desain & Hasil \\
\hline 1 & $\begin{array}{l}\text { Fereshteh } \\
\text { Jahdi et al, } \\
2016\end{array}$ & $\begin{array}{l}\text { The effect of slow } \\
\text { stroke back } \\
\text { massage on the } \\
\text { anxiety levels of } \\
\text { Iranian women on } \\
\text { the first } \\
\text { postpartum day }\end{array}$ & $\begin{array}{l}\text { Untuk menentukan } \\
\text { efektivitas slow } \\
\text { stroke back massage } \\
\text { pada tingkat } \\
\text { kecemasan ibu } \\
\text { primipara di hari-hari } \\
\text { pertama setelah } \\
\text { kelahiran. }\end{array}$ & $\begin{array}{l}\text { Single-blind } \\
\text { randomized } \\
\text { controlled } \\
\text { clinical trial }\end{array}$ & 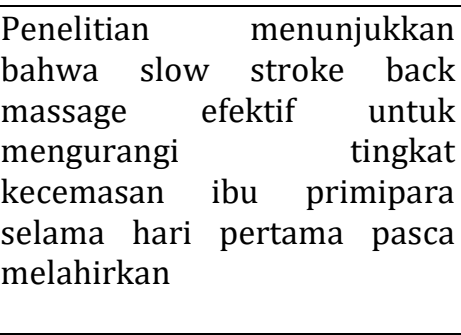 \\
\hline 2 & $\begin{array}{l}\text { Maryam } \\
\text { Kianpour } \\
\text { et al, } 2019\end{array}$ & $\begin{array}{l}\text { Effect of lavender } \\
\text { scent inhalation } \\
\text { on prevention of } \\
\text { stress, anxiety and } \\
\text { depression in the } \\
\text { postpartum period }\end{array}$ & $\begin{array}{l}\text { Untuk mengetahui } \\
\text { efek lavender dalam } \\
\text { pencegahan stress, } \\
\text { kecemasan dan } \\
\text { depresi pada ibu } \\
\text { postpartum. }\end{array}$ & $\begin{array}{c}\text { Randomize } \\
\text { d control } \\
\text { trial }\end{array}$ & 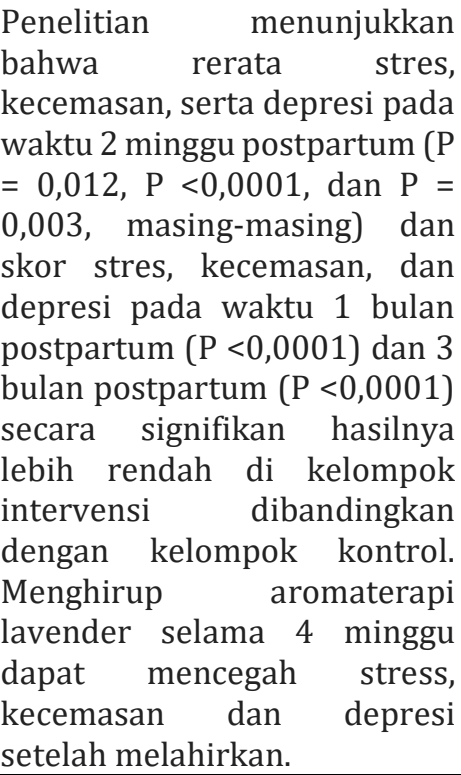 \\
\hline
\end{tabular}

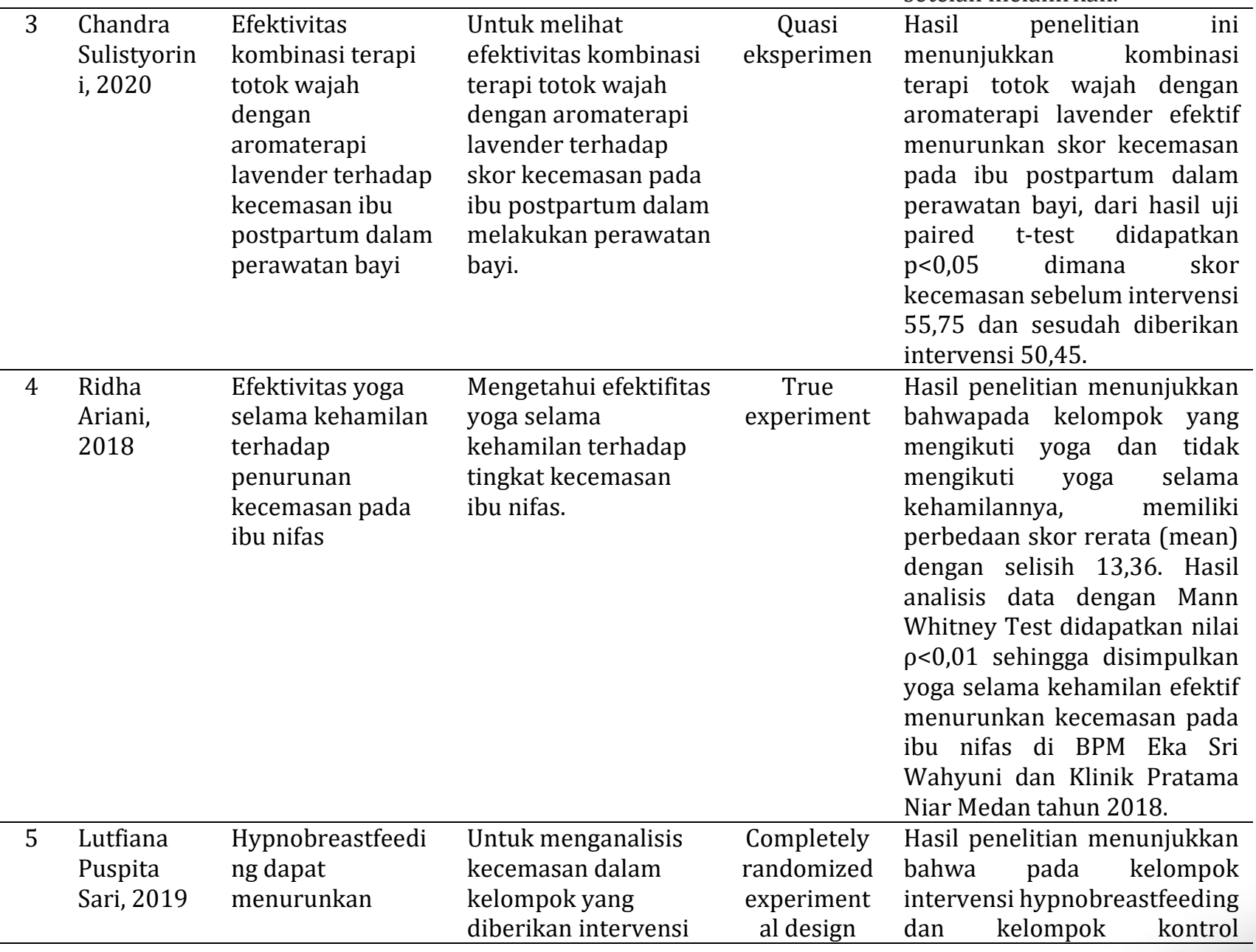




\begin{tabular}{|c|c|c|c|c|c|}
\hline No & Penulis & Judul & Tujuan & Desain & Hasil \\
\hline & & $\begin{array}{l}\text { kecemasan pada } \\
\text { ibu postpartum }\end{array}$ & $\begin{array}{l}\text { hypnobreastfeeding } \\
\text { dan kelompok } \\
\text { kontrol. }\end{array}$ & & $\begin{array}{lcr}\text { terdapat } & \text { perbedaan } & \text { yang } \\
\text { signifikan antara } & \text { tingkat } \\
\text { kecemasan } & \text { yang } & \text { dialami, } \\
\text { diperoleh nilai } & \text { p=0,002 } \\
\text { sehingga disimpulkan } & \text { bahwa } \\
\text { hypnobreastfeeding } & \text { efektif } \\
\begin{array}{l}\text { menurunkan } \\
\text { kecemasan }\end{array} & \text { tingkat } \\
\text { postpartum. } & & \text { ibu } \\
\end{array}$ \\
\hline
\end{tabular}

\begin{tabular}{|c|c|c|c|c|}
\hline 6 & $\begin{array}{l}\text { Tina } \\
\text { Mawardika } \\
, 2020\end{array}$ & $\begin{array}{l}\text { Penerapan } \\
\text { relaksasi otot } \\
\text { progresif terhadap } \\
\text { penurunan } \\
\text { kecemasan ibu } \\
\text { postpartum }\end{array}$ & $\begin{array}{l}\text { Untuk mengetahui } \\
\text { efektifitas relaksasi } \\
\text { otot progresif untuk } \\
\text { menurunkan } \\
\text { kecemasan ibu } \\
\text { postpartum. }\end{array}$ & $\begin{array}{c}\text { Randomize } \\
\text { d Control } \\
\text { Trial }\end{array}$ \\
\hline
\end{tabular}

Diperoleh hasil penelitian

Diperoleh hasil penelitian
bahwa terapi relaksasi otot progresif efektif mengurangi kecemasan ibu nifas, ditunjukkan dengan hasil uji statistic MD $(95 \% \mathrm{CI})=-10,11$, 642 dan $\mathrm{p}=0,02$. Menurut hasil uji statistic pada alpha 0,05 terdapat perbedaan kecemasan ibu nifas yang signifikan pada kelompok intervensi sebelum serta setelah diberikan terapi relaksasi otot progresif $(\mathrm{p}=$ 0,001) dan hal ini menunjukkan bahwa terapi relaksasi otot progresif dapat menurunkan kecemasan ibu nifas sebesar 11, 237.

\begin{tabular}{|c|c|c|c|c|c|}
\hline 7 & $\begin{array}{l}\text { Sri Rahayu, } \\
2018\end{array}$ & $\begin{array}{l}\text { Pengaruh masase } \\
\text { endorphin } \\
\text { terhadap tingkat } \\
\text { kecemasan dan } \\
\text { involusio uteri ibu } \\
\text { nifas }\end{array}$ & $\begin{array}{l}\text { Untuk menganalisis } \\
\text { efek pemijatan } \\
\text { endorphine terhadap } \\
\text { kecemasan serta } \\
\text { involusio uteri ibu } \\
\text { postpartum. }\end{array}$ & $\begin{array}{l}\text { Quasi- } \\
\text { experiment } \\
\text { with a pre- } \\
\text { post-test } \\
\text { with control } \\
\text { group } \\
\text { design. }\end{array}$ & $\begin{array}{l}\text { Hasil penelitian menunjukkan } \\
\text { sebelum perlakuan sebagian } \\
\text { besar responden mengalami } \\
\text { kecemasan sedang (69\%), dan } \\
\text { rata-rata tinggi uteri fundus } \\
10,5 \mathrm{~cm} \text {. Uji t independen } \\
\text { menunjukkan ada pengaruh } \\
\text { pijat endorfin tingkat } \\
\text { kecemasan (nilai p = 0,001) } \\
\text { dan tidak ada pengaruh } \\
\text { terhadap involusi uterus (hal } \\
\text { nilai = 0,302). Pijat endorphin } \\
\text { dilakukan oleh suami kepada } \\
\text { ibu postpartum } \\
\text { berkontribusi sangat baik } \\
\text { untuk menurunkan } \\
\text { kecemasan ibu dan } \\
\text { meningkatkan rasa } \\
\text { kepercayaan diri. }\end{array}$ \\
\hline 8 & $\begin{array}{l}\text { Junaida } \\
\text { Rahmi, } \\
2020\end{array}$ & $\begin{array}{l}\text { Pengaruh } \\
\text { perawatan } \\
\text { payudara } \\
\text { terhadap } \\
\text { kelancaran ASI } \\
\text { dan tingkat } \\
\text { kecemasan pada } \\
\text { ibu nifas }\end{array}$ & $\begin{array}{l}\text { Untuk mengetahui } \\
\text { adanya pengaruh dari } \\
\text { perawatan payudara } \\
\text { terhadap kelancaran } \\
\text { produksi asi serta } \\
\text { tingkat kecemasan } \\
\text { pada ibu postpartum }\end{array}$ & $\begin{array}{l}\text { Quasi } \\
\text { experiment } \\
\text { with Two } \\
\text { Groups } \\
\text { Pretest- } \\
\text { Posttest } \\
\text { Design }\end{array}$ & 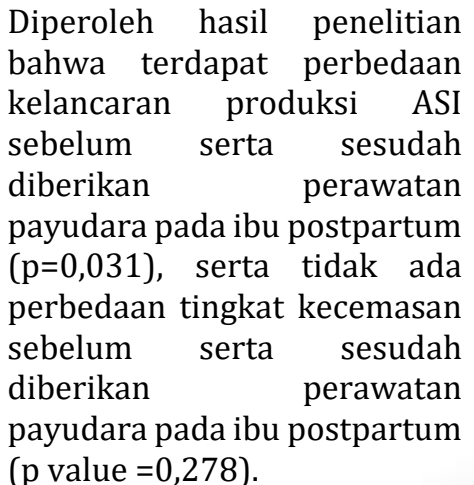 \\
\hline
\end{tabular}




\begin{tabular}{|c|c|c|c|c|c|}
\hline No & Penulis & Judul & Tujuan & Desain & Hasil \\
\hline 9 & $\begin{array}{l}\text { Siti Novy } \\
\text { Romlah, } \\
2019\end{array}$ & $\begin{array}{l}\text { Pengaruh pijat } \\
\text { oketani terhadap } \\
\text { kelancaran asi dan } \\
\text { tingkat kecemasan } \\
\text { pada ibu nifas }\end{array}$ & $\begin{array}{l}\text { Untuk mengetahui } \\
\text { pengaruh pemberian } \\
\text { pemijatan oketani } \\
\text { terhadap kelancaran } \\
\text { ASI dan tingkat } \\
\text { kecemasan pada ibu } \\
\text { postpartum. }\end{array}$ & $\begin{array}{l}\text { Quasi } \\
\text { experiment } \\
\text { with One } \\
\text { Groups } \\
\text { Pretest- } \\
\text { Posttest } \\
\text { Design }\end{array}$ & $\begin{array}{l}\text { Didapatkan hasil penelitian } \\
\text { yaitu mean kelancaran } \\
\text { produksi ASI sebelum serta } \\
\text { sesudah pemijatan oketani } \\
\text { pada ibu postpartum adalah } \\
10,3 \text { dan 12,5, hasil uji t } \\
\text { dependen didapatkan adanya } \\
\text { perbedaan kelancaran } \\
\text { produksi ASI sebelum serta } \\
\text { sesudah diberikan pemijatan } \\
\text { oketani pada ibu postpartum } \\
\text { (p=0,016). Mean tingkat } \\
\text { kecemasan sebelum serta } \\
\text { sesudah diberikan pemijatan } \\
\text { oketani pada ibu postpartum } \\
\text { adalah 35,11 dan 13,33. } \\
\text { Hasilnya diperoleh adanya } \\
\text { beda tingkat kecemasan } \\
\text { sebelum serta sesudah } \\
\text { diberikan pemijatan oketani } \\
\text { pada ibu postpartum } \\
\text { (p=0,006). }\end{array}$ \\
\hline
\end{tabular}

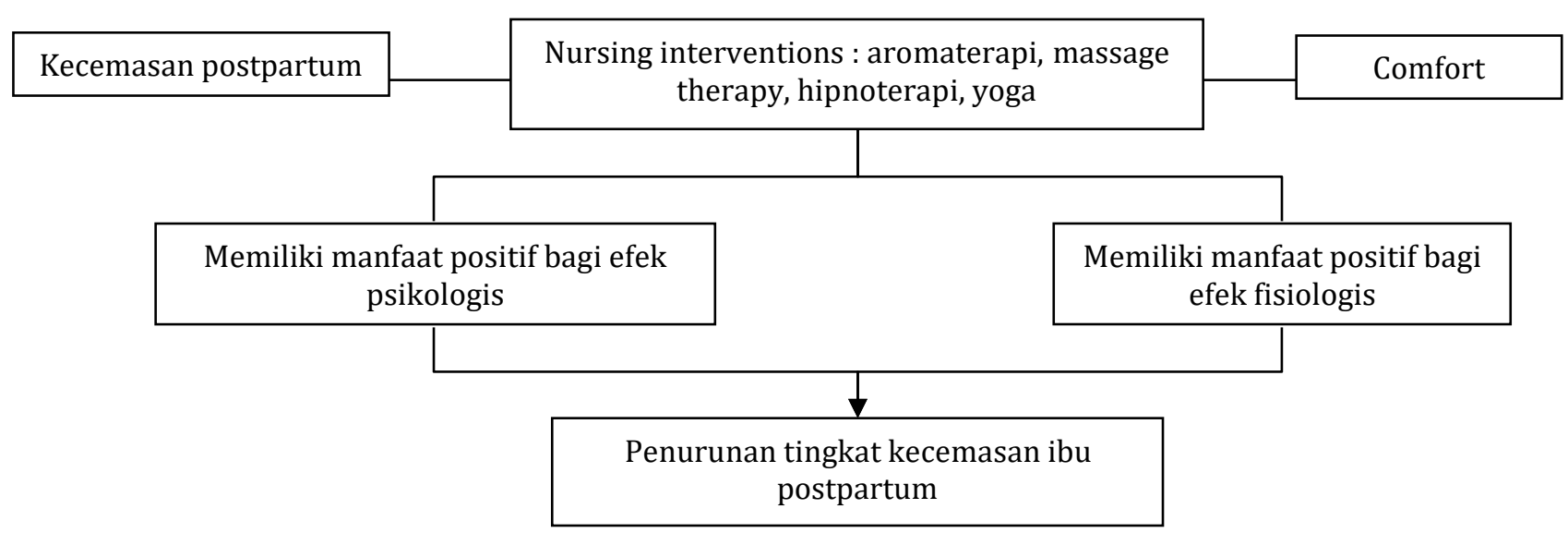

Gambar 2.

Analisis Sintesis Intervensi untuk Menurunkan Kecemasan Postpartum

\section{PEMBAHASAN}

Tujuan dari sistematis ini adalah mendapatkan beberapa intervensi yang bisa dipergunakan untuk menurunkan tingkat kecemasan pada ibu postpartum. Berdasarkan analisis artikel didapatkan bahwa ada beberapa intervensi yang dapat dipergunakan untuk menurunkan tingkat kecemasan pada ibu postpartum, antara lain : massage therapy, yoga, hypnoterapi, aromaterapi dan relaksasi otot progresif.
Ibu nifas memiliki emosi berlebihan yang mengakibatkan suatu perasaan cemas yang akan muncul antara kebahagiaan serta rasa nyeri yang sedang dialami. Salah satu sumber perasaan cemas yang dialami merupakan objektif ansietas primer yang muncul akibat trauma saat persalinan (birth trauma), yang menjadi dasar bagi terciptanya neurotic anxiety. Kondisi cemas dimana manusia selalu menunggu suatu hal buruk yang dapat terjadi, akhirnya manusia tersebut senantiasa ditempatkan dalam kondisi cemas sebab memiliki rasa takut 
mengalami dampak yang akan buruk dalam menghadapi situasi yang tidak tentu, kondisi ini dapat dikatakan sebagai freefloating anxiety [11].

Pada kondisi setelah persalinan, kadar estrogen serta progesteron pada tubuh menurun, ibu terkadang merasa kelelahan setelah melahirkan serta merasakan nyeri pada perineum. Ibu dapat merasa sangat tertekan serta dapat menangis untuk hal yang tidak dipahami.

Perasaan cemas terhadap kemampuan dirinya dalam hal mengurus dan menjaga bayi setelah selesai perawatan di rumah sakit serta perasaan takut menjadi tidak menarik untuk suami adalah adaptasi psikologis yang dialami oleh ibu postpartum. Perubahan secara tiba-tiba pada kondisi hormonal menyebabkan ibu postpartum menjadi lebih sensitif terhadap hal yang dapat ditangani dalam kondisi normal [11].

Kecemasan adalah perasaan personal dimana terdapat reaksi secara umum atas ketidakmampuan dalam menangani suatu kesulitan ataupun hilangnya rasa aman yang berbentuk ketegangan mental yang membuat gelisah yang akhirnya akan memunculkan ataupun ditandai dengan perubahan fisiologis serta psikologis [12]. Rasa cemas adalah salah satu ketidaknyamanan psikologis yang dialami oleh ibu postpartum [13].

Manajemen kecemasan non farmakologi antara lain :

\section{Aromaterapi}

Aromaterapi digunakan sebagai salah satu alternatif untuk mengurangi ketidaknyamanan baik fisik maupun psikologis secara non famakologi. Aromaterapi memiliki efek positif, sebab aroma yang menyegarkan serta harum dapat menstimulus sensori serta reseptor yang berada di hidung; lalu memberi perintah ke otak yang mempunyai control pada emosi dan memori serta memberi informasi pada hipotalamus, sebagai pengatur sistem internal tubuh, termasuk sistem seksualitas, suhu tubuh, serta reaksi terhadap stres [14]. Inhalasi aromaterapi dapat menurunkan tingkat kecemasan seseorang. Tiap-tiap minyak essensial aromaterapi mempunyai efek farmakologis yang unik, antara lain sebagai penenang, antibakteri, antivirus, diuretik, vasodilator, serta merangsang adrenal [15]. Aroma pada essensial oil memberi efek positif terhadap system saraf pusat, dengan menghambat pengeluaran Adreno Corticotriphic Hormone (ACTH) yaitu hormon yang menyebabkan terjadinya kecemasan pada sesorang [16].

\section{Massage Therapy}

Massage adalah satu dari beberapa metode pilihan yang sangat safety serta mempunyai manfaat untuk pemulihan tubuh. Massage menaikkan produksi serotonin yang menyebabkan berkurangnya hormon kortisol, berkurangnya depresi serta dapat menyebabkan bertambahnya dopamin, berkurangnya norepinephrin serta berkurangnya rasa cemas. Membuat imunitas ibu postpartum akan meningkat sehingga dapat mempercepat pemulihan kondisi fisik serta mental ibu [17]. Terapi pijat akan memberikan rasa rileks, lega serta nyaman secara menyeluruh pada pasien. Rileksasi dapat menekan perasaan tegang serta kecemasan yang dapat menstimulus hipotalamus [8]. Pemijatan pada tulang belakang neuro transmitter akan menstimulus medula oblongata untuk memberikan sinyal kepada hipotalamus di hypofisis anterior agar memproduksi oksitosin supaya menghasilkan air susu. Pemijatan di area tulang belakang ini dapat menurunkan ketegangan, stress hilang serta kecemasan sehingga hormon oksitosin akan diproduksi serta dapat membantu produksi air susu ibu [18]

\section{Hipnoterapi}

Hipnoterapi dapat membuat gelombang otak dapat sampai pada gelombang alfa, 
pada saat gelombang alfa mencapai otak, tubuh serta pikiran menjadi rileks, tetapi tetap waspada. Tubuh memproduksi hormon serotonin serta endorphin, yang memiliki manfaat guna menekan hormon ACTH, hormon yang mengatur sekresi kortisol yang menyebabkan stres serta cemas [19].

Yoga

Yoga mempunyai manfaat dapat meminimalkan ketegangan tubuh, pikiran, juga mental serta menjadikan tubuh lebih kuat saat menghadapi stres dan cemas, membuat rasa percaya diri meningkat, selalu berfikir positif serta dapat meningkatkan hormon endorphin [4].

Terapi akupuntur

Terapi akupuntur adalah salah satu intervensi komplementer guna menurunkan kecemasan serta stres. Dengan melakukan penekanan pada titiktitik akupuntur yang mempunyai tujuan agar mengirimkan sinyal yang dapat menyeimbangkan system syaraf dengan memproduksi hormone endorphin untuk meningkatkan kenyamanan serta mengurangi kecemasan, stress serta rasa sakit [20].

\section{SIMPULAN}

Tujuan penelitian dari tinjauan ini adalah menemukan beberapa literatur-literatur yang bisa digunakan untuk menurunkan tingkat kecemasan pada ibu postpartum dan menunjukan berbagai macam tindakan dari berbagai intervensi yang bisa diberikan pada ibu postpartum. Tinjauan ini dapat membantu memberikan informasi tentang beberapa jenis intervensi yang dapat diberikan kepada ibu postpartum. Secara keseluruhan, tindakan non farmakologis yang dapat diberikan sangat sederhana serta efektif dalam penurunan tingkat kecemasan pada ibu postpartum. Intervensi lainnya juga mempunyai efek meningkatkan kualitas tidur, mengurangi tingkat depresi, mengurangi stress, dapat meningkatkan produksi asi serta meningkatkan kenyamanan pada ibu postpartum.

\section{UCAPAN TERIMAKASIH}

Penulis memberikan ucapan terimakasih kepada semua pihak yang telah mendukung dalam penulisan studi literatur ini.

\section{REFERENSI}

[1] Motzfeldt I, Andreasen S, Pedersen AL, Pedersen ML. Prevalence of postpartum depression in Nuuk, Greenland - A crosssectional study using Edinburgh Postnatal Depression Scale. Int J Circumpolar Health 2013;72.

https://doi.org/10.3402/ijch.v72i0.21114.

Basri AH, Zulkifli A, Abdullah MT, Basri AH, Km S. Efektivitas psikoedukasi terhadap depresi postpartum di rsia Sitti Fatimah dan rsia Pertiwi Makassar tahun 2014. Univ Hasanuddin 2014:1-12.

[3] Chandra Sulistyorini, Desy Ayu Wardani A. Efektivitas kombinasi terapi totok wajah dengan aroma terapi lavender terhadap kecemasan ibu postpartum dalam perawatan bayi. J Med Karya Ilm Kesehat 2020;5:1-8.

[4] Ariani R. Efektivitas yoga selama kehamilan terhadap penurunan kecemasan pada ibu nifas di klinik Eka Sri Wahyuni dan klinik pratama Niar tahun 2018. 2018.

[5] Sari LP, Salimo H, Budihastuti UR. Hypnobreastfeeding Dapat Menurunkan Kecemasan Pada Ibu Post Partum. J Kebidanan Dan Kesehat Tradis 2019;4:20-7. https://doi.org/10.37341/jkkt.v4i1.95.

[6] Mawardika T, Umi Aniroh, Lestari P, Tina Mawardika, Umi Aniroh PL. Penerapan relaksasi otot progresif terhadap penurunan kecemasan ibu post partum. J Gizi Dan Pangan 2020;12:277-86.

[7] Rahayu S, Widyawati MN, Dewi RK. Pengaruh masase endorphin terhadap tingkat kecemasan dan involusio uteri ibu nifas. J Kebidanan 2018;8:29. https://doi.org/10.31983/jkb.v8i1.3732.

[8] Romlah SN, Rahmi J. Pengaruh pijat oketani terhadap kelancaran asi dan tingkat kecemasan pada ibu nifas. Edudharma J 2019;3:90-102.

[9] Kianpour M, Mansouri A, Mehrabi T, Asghari G. Effect of lavender scent inhalation on 
prevention of stress, anxiety and depression in the postpartum period. Iran J Nurs Midwifery $\quad$ Res 2016;21:197. https://doi.org/10.4103/17359066.178248.

[10] Jahdi F, Mehrabadi M, Mortazavi F, Haghani H. The effect of slow-stroke back message on the anxiety levels of Iranian women on the first postpartum day. Iran Red Crescent Med J 2016;18. https://doi.org/10.5812/ircmj.34270.

[11] Husen K, Wardani ND, Puspitasari VD. Pengaruh pemberian konseling individu sebelum melahirkan terhadap tingkat kecemasan pada ibu postparrtum. J Kedokt Diponegoro 2017;6:682-91.

[12] Rohman KL. Kesehatan mental. Purwokerto: Fajar Media Press; 2010.

[13] Yes,im Aksoy Derya, Türkan Pasinliog lu. The effect of nursing care based on comfort theory on women's postpartum comfort levels after caesarean sections. Int J Nurs Knowl 2017;28:138-44. https://doi.org/10.1111/2047-3095.12122.

[14] Rahmah F, Astutiningrum D. Penerapan aromaterapi minyak sereh terhadap pencegahan gejala post partum blues pada ibu primipara di RSUD Dr . 2019:116-21.

[15] Syukrini RD. Pengaruh aromaterapi terhadap tingkat kecemasan pada ibu persalinan kala I di kamar bersalin Rsu Kab. Tangerang. 2016.

[16] Conrad P, Adams C. The effects of clinical aromatherapy for anxiety and depression in the high risk postpartum woman - A pilot study. Complement Ther Clin Pract 2012;18:164-8.

https://doi.org/10.1016/j.ctcp.2012.05.002.

[17] Maharani K, Anwar C, Suwandono A. Kombinasi herbal steam bath dan massage terapi pada ibu nifas dalam mencegah post partum blues. J Keperawatan Silampari 2019;2:123-33. https://doi.org/e-ISSN: 2581-1975 p-ISSN: 2597-7482 DOI: https://doi.org/10.31539/jks.v2i2.509.

[18] Suraidi DA. Pengaruh pijat oksitosin terhadap perubahan kecemasan pada ibu menyusui di Kelurahan Merjosari Kecamatan Lowokwaru Malang. University of Muhammadiyah Malang, 2018.

[19] Fadilah WN, Megawati M, Astiriyani E. Pengaruh hipnosis terhadap tingkat kecemasan ibu post sectio caesarea. Media Inf 2018;14:148-53. https://doi.org/10.37160/bmi.v14i2.214.

[20] Sumantri, Susilowati D, Wati DK. Penurunan kecemasan ibu nifas menggunakan totok wajah di fasilitas pelayanan persalinan 2014;00:34-9. 